\title{
O público e o privado na educação profissional: um estudo sobre a execução do Pronatec na rede federal e no SENAI
}

\author{
Public and private at professional education: a study on Pronatec execution at \\ the federal network and at SENAI \\ Lo público y lo privado en la formación profesional: un estudio sobre la \\ ejecución de Pronatec en la red federal y en SENAI
}

\section{MARCELO LIMA \\ ZILKA SULAMITA TEIXEIRA DE AGUILAR PACHECO \\ ANA PAULA RIBEIRO FERREIRA \\ SAMANTA LOPES MACIEL}

\begin{abstract}
Resumo: Com objetivo de analisar o processo de mercantilização da política de educação profissional no Brasil, realizou-se uma pesquisa comparativa entre a execução do Pronatec pela rede Federal e pelo Sistema S no Brasil e no ES. Os dados afirmam que maior parte dos recursos fora destinada ao setor privado, com destaque para o SENAI, com 35\%. Tal política, no contexto de crise do capital, pretende priorizar a oferta de cursos de curta duração, frear a expansão da rede federal, de modo a solucionar a problemática da formação para o mercado por meio da criação do mercado da formação.
\end{abstract}

Palavras-chave: Educação profissional; Pronatec; mercantilização.

Abstract: Aiming to analyze the commercialization process of Professional Education policy in Brazil, a comparative survey, of the implementation of the Federal Pronatec network and the S System in Brazil and ES, were realized. The data say that most of the funds had been assigned to the private sector, highlighting the SENAI with $35 \%$. Such a policy, in the context of the financial crisis, intends to prioritize the provision of short courses and to halt the expansion of the federal system, in order to solve the problems of education to the market through the creation of the training market.

Keywords: Professional education; Pronatec; training market.

Resumen: Con el objetivo de analizar el proceso de mercantilización de la política de educación profesional en Brasil, se realizó un estudio comparativo entre la ejecución de Pronatec por la red federal y por el Sistema S en Brasil y en ES. Los datos afirman que la mayor parte de los fondos se habían asignado al sector privado, destacándose SENAI con el 35\%. Tal política, en el contexto 
de crisis del capital, pretende dar prioridad a la oferta de cursos corta duración, frenar la expansión de la red federal de modo a solucionar la problemática de la formaciónpara el mercado a través de la creación del mercado de la formación.

Palabras clave: Educación professional; Pronatec; mercantilización.

\section{INTRODUÇÃO}

Este artigo discute a relação entre o público e o privado na oferta de educação profissional no Brasil, a partir de um estudo comparativo entre a execução do Programa Nacional de Acesso ao Ensino Técnico e Emprego (Pronatec) pela Rede Federal e pelo Sistema S, em nível nacional e no Espírito Santo. Como fonte de dados, recorremos à análise documental dos relatórios de gestão da Secretaria de Educação Profissional e Tecnológica (Setec) e do Sistema Nacional de Informações da Educação Profissional e Tecnológica (Sistec), ambos ligados ao Ministério da Educação (MEC), bem como ao relatório de auditoria da Controladoria Geral da União (CGU), todos referentes ao ano de 2013.

Pautando-nos em uma orientação teórica marxiana, buscamos estabelecer diálogo com a produção referente à concepção e papel do Estado, do público e do privado, tendo em vista o direito à educação. Dessa forma, partimos de uma perspectiva de qualificação profissional emancipadora, que supere os processos de alienação típicos da divisão do trabalho no capitalismo e que, portanto, tome o trabalho nas suas contradições, sem perder de vista seu caráter ontológico e educativo.

Consideramos importante situar historicamente as duas instituições citadas, dado que a Rede Federal e o Senai surgem em contextos históricos, políticos e econômicos diferenciados, possuindo também distintas finalidades, conforme observado por Cunha (2000). Buscamos ainda tecer considerações sobre possíveis aproximações e distanciamentos entre as instituições no que se refere à abrangência, área de atuação, modalidades e cursos ofertados. Partindo do entendimento do trabalho como direito de todo o cidadão, pretendemos colaborar com as reflexões sobre o papel do Estado na garantia da qualificação profissional, pontuando as implicações da oferta por meio da esfera pública e/ou privada.

Quanto à estrutura, o artigo está assim organizado: a seção 2 caracteriza os institutos federais e o Sistema S; a seção 3 compara a participação de ambos na oferta de cursos do Pronatec, nacional e localmente, mostrando a proeminência das matrículas no Senai, mesmo em um contexto em que a rede federal possui 
uma estrutura física bem maior, evidenciando, na seção 4, que tal programa tem sido alternativa para solucionar a problemática da formação para o mercado, criando um mercado da formação.

\section{A REDE NACIONAL DE EDUCAÇÃO PROFISSIONAL: INSTITUTOS FEDERAIS E SISTEMA S}

Até o início do século XX, para a quase totalidade da população, a aprendizagem do processo produtivo se dava por meio da inserção precoce dos jovens no trabalho. Essa forma de inserção produtiva e formativa foi denominada por Mange (1953) aprendizagem assistemática dos ofícios. Foi somente no início do século passado, por intermédio do Decreto n ${ }^{\circ} 7.566 / 1909$, que instituiu as escolas de aprendizes e artífices, que se deu início ao processo de implantação da aprendizagem racional, cuja consolidação se efetivou nas experiências de ensino metódico nas escolas ferroviárias, implementadas a partir de $1920^{1}$.

Quase duas décadas antes da criação do Senai, inicialmente no Liceu de Artes em Mecânica, em São Paulo, e, depois, no Centro de Formação e Seleção Profissional de São Paulo, este considerado embrião da pedagogia do Sistema S, Mange (1953) vai criar a aprendizagem racional no Brasil e implantar o modelo taylorista-fordista de formação para o trabalho, cujos fundamentos estabeleciam que os aprendizes devessem estudar antes de produzir e que os educandos deveriam ser selecionados por meio da psicotécnica, devendo os objetivos educacionais ser racionais, em vez de assistenciais ${ }^{2}$.

Dessa forma, com base na vontade política e a partir da necessidade da reprodução da força de trabalho - inicialmente ferroviária, mas, depois, industrial - foram forjadas, ao longo do tempo, duas redes de escolas de formação profissional, erguidas sobre dois pilares distintos, a saber: Sistema S e Rede Federal de Educação Profissional. Tais subsistemas permaneceram por muitos anos alheios ao sistema escolar brasileiro, cujo objetivo principal foi, historicamente, o de garantir ao governo federal, por um lado, e ao setor empresarial, por outro, o controle da oferta de um tipo de ensino considerado estratégico para a reprodução da força de trabalho no Brasil.

Cunha (2000), ao tratar das práticas pedagógicas e dos processos de criação e de localização das duas redes, distingue como cada uma delas apresenta, em sua base, um tipo e grau de vinculação aos interesses políticos e econômicos de determinada época. No início, a Rede Federal, embora assumisse um discurso

1 Para maior aprofundamento, ver Fonseca (1986), Medeiros (1987) e Bryan (1992).

2 Sobre Roberto Mange, ver Bologna (1980) e Fonseca (1986). Ver Decreto no 7566 de 1909. 
industrialista, atendia a interesses mais assistencialistas que pedagógicos. Em 1942, a criação do Senai e a transformação das escolas de aprendizes e liceus industriais em escolas técnicas vai constituir um "sistema" paralelo de formação profissional, no qual cada rede, Sistema S e escolas técnicas federais, terão funções sociais pedagogicamente muito parecidas, embora não idênticas.

Tanto o Sistema S quanto a Rede Federal são mantidos, desde sua criação, pelo fundo público, diferenciando-se em sua gestão. Enquanto o primeiro é gestionado pelo sistema patronal empresarial, composto por diversos setores da economia, organizados em federações estaduais e confederações nacionais, o segundo está submetido diretamente à gestão do governo federal.

Menos intensivamente, de 1909 a 1942 (fase correcional-assistencialista), e mais intensivamente, de 1942 a 1990 (fase taylorista-fordista), a Rede Federal foi mudando seu público-alvo, bem como transitou de uma oferta escolar na forma de cursos industriais básicos para a de cursos técnicos e de ensino médio, numa perspectiva politécnica. $\mathrm{Na}$ fase taylorista-fordista, o Sistema S permaneceu com seu foco nos cursos de aprendizagem, numa perspectiva multitécnica ${ }^{3}$.

\section{DIMENSÕES DA REDE FEDERAL E DO SENAI: ANÁLISE COMPARATIVA DA PARTICIPAÇÃO NACIONAL E LOCAL NA OFERTA DE CURSOS DO PRONATEC}

A partir dos dados do Sistec referentes a 2015, o MEC (acesso em 5out. 2015) informa que a Rede Federal conta hoje com 67 instituições (38 institutos federais, 25 escolas vinculadas às universidades federais, dois centros federais de educação tecnológica e uma universidade tecnológica), totalizando cerca de 800 mil matrículas em 550 campi. Por sua vez, o Senai conta com 28 departamentos regionais (um por estado e Distrito Federal), com cerca de 3,6 milhões de matrículas em pouco mais de 800 unidades em todo o País (SENAI, acesso em 20 set. 2015). No Espírito Santo, o Instituto Federal de Educação Ciência e Tecnologia (Ifes) possui 21 campi e pouco mais de 18 mil matrículas/ano (INSTITUTO FEDERAL DE EDUCAÇÃO, CIÊNCIA E TECNOLOGIA DO ESPÍRITO SANTO, 2014), enquanto o Senai-ES possui dez unidades de ensino, com cerca de 150 mil alunos (PRONATEC, acesso em 20 set. 2015).

A comparação entre a infraestrutura física das duas redes deve ser cuidadosa, pois o tamanho médio das unidades de ensino, assim como sua distribuição no País e em cada estado, é muito diferente. De modo geral, as escolas da Rede Federal possuem estrutura física maior do que os estabelecimentos de

3 Para maior aprofundamento, ver Lima (2007, 2010 e 2011), Kuenzer (1999) e Cunha (2000).

874 - RBPAE - v. 32, n. 3, p. 871 - 885 set./dez. 2016 
ensino do Senai. No entanto, a distribuição da base territorial deste assemelha-se à capilaridade da indústria, o que não se repete quando Observamos a localização dos campi dos institutos federais, que não atendem apenas a demandas do setor secundário, seguindo uma lógica mais política do que econômica, como descreve Cunha (2000).

Em termos quantitativos, o número de estabelecimentos do Senai no País é maior que o número de campi da Rede Federal. Porém, no Espírito Santo, ocorre o contrário: o número de campi do Instituto Federal do Espírito Santo (IFES) é o dobro do número de unidades do Senai-ES ${ }^{4}$. Em relação ao número de matrículas, os dados revelam uma enorme superioridade do Senai, que, em nível nacional, apresenta cinco matrículas para cada matrícula da Rede Federal. Em termos locais, cada matrícula do IFES corresponde a oito no Senai-ES.

Esse processo se explica pelos diferentes tipos de cursos ofertados historicamente em cada uma das redes. Tradicionalmente, o Senai esteve voltado para cursos de aprendizagem industrial de dois anos de duração (cerca de 1.600 horas), de formação multitécnica, enquanto as então escolas técnicas federais (ETF), denominação que precedeu os centros federais de educação tecnológica e os institutos federais, ofertavam cursos técnicos profissionalizantes no modelo da Lei de Diretrizes e Bases da Educação Nacional (LDB) n 5.692/1971, que tentou generalizar a oferta do ensino politécnico para toda a rede de ensino de $2^{\circ}$ grau, atual ensino médio (BRASIL, 1971).

Os cursos ofertados pela Rede Federal na fase da "cefetização" e da "ifetização" sofreram um deslocamento no sentido de uma maior diversificação, para além do então ensino de $2^{\circ}$ grau profissionalizante. Na fase da "cefetização" (1997-2004), denominada por Cunha (2000) como “senaização” das ETFs, quando vigorou o Decreto no 2.208/1997 (BRASIL, 1997), no leque de cursos, passaram a ser mais contemplados os níveis básico, técnico e tecnológico. Nessa fase, foi abolida a oferta do ensino médio e os cursos passaram a ter duração média que oscilava entre algumas centenas de horas, no caso dos cursos básicos, podendo chegar a 2.000 horas (cerca de dois anos), quando na forma de cursos técnicos pós-médio e tecnológicos. Com a promulgação do Decreto no 5.154/2004, houve uma expansão da Rede Federal, que passou a ofertar também cursos técnicos integrados ao ensino médio, com cargas horárias chegando a 4.000 horas (três a quatro anos) (BRASIL, 2004).

Aqui não estamos considerando os polos de educação a distância do Ifes nem as unidades móvei do Senai-ES. Também não consideramos, em termos locais e nacionais, as redes de outras instituições $S$ (Serviço Nacional de Aprendizagem do Comércio, Serviço Nacional de Aprendizagem Rural, Serviço Social do Transporte e Serviço Brasileiro de Apoio às Micro e Pequenas Empresas). 
O Senai, por sua vez, na lógica que Cunha (2000) denominou autoprivatização, e que Lima (2011) denominou mercantilização, abandonou progressivamente a hegemonia dos cursos de aprendizagem industrial (LIMA, 2007), razão pela qual, atualmente, sua oferta é, predominantemente, composta por cursos de qualificação e aperfeiçoamento profissional, com cargas horárias de baixa e média duração (variando de 160 a 400 horas e de 16 a 120 horas, respectivamente). Também figuram outras formas, como cursos técnicos concomitantes e subsequentes, às vezes, em articulação com o Serviço Social da Indústria, constituindo serviços em geral vendidos à população e às empresas. Graças a acordo com o governo federal realizado na gestão Lula, o sistema também oferece, em menor quantidade, as modalidades de aprendizagem e técnicos gratuitos para pessoas de baixa renda.

No contexto atual, tanto a Rede Federal quanto o Senai ofertam uma gama de cursos em áreas profissionais bastante diversificadas, cobrindo numerosos setores da economia e arranjos produtivos. No entanto, as duas redes diferenciam-se, de modo que os cursos tecnológicos e técnicos preponderam no conjunto da oferta federal, que chega a manter cursos de pós-graduação.

No Senai, atualmente a forma de curso predominante não mais é a aprendizagem industrial, mas a qualificação e o aperfeiçoamento profissional. Desse modo, essa instituição mantém, hoje, mais alunos, matriculados em maior quantidade de cursos, embora mais rápidos, enquanto a Rede Federal tem menos alunos, ofertando menos cursos, porém, com maior duração.

$\mathrm{Na}$ seção seguinte, analisaremos a participação dos setores público e privado no Pronatec, bem como os tipos de cursos ofertados, a fim de comparar o papel do Senai e da Rede Federal nesse programa.

\section{O PRONATEC NA REDE FEDERAL E NO SENAI}

Em relação aos dados do Pronatec, o relatório de gestão da Setec/ MEC aponta que de 2011 a 2014 foram realizadas cerca de seis milhões de matrículas ${ }^{5}$, compreendendo as cinco ações do programa (Bolsa-Formação, Brasil Profissionalizado, Rede e-Tec Brasil, acordo com o Sistema S e Rede Federal). Desse total, conforme podemos observar na Tabela 1 , cerca de 1,7 milhão de matrículas sé destinaram aos cursos técnicos e aproximadamente quatro milhões se voltaram aos cursos de Formação Inicial e Continuada (FIC) (MEC, 2014, p. 21).

5 O referido relatório indica número de vagas ofertadas do número de vagas efetivamente preenchidas. Para este artigo, estamos considerando o número de vagas preenchidas. 
Tabela 1: Vagas ofertadas por meio do Pronatec no período 2011-2014

\begin{tabular}{|c|c|c|c|c|c|c|}
\hline & & 2011 & 2012 & 2013 & 2014 & Total \\
\hline \multirow{2}{*}{ Bolsa-Formação } & Previsto & 9.415 & 99.149 & 151.313 & 151.313 & 411.190 \\
\hline & Realizado & 0 & 101.541 & 304.966 & & 406.507 \\
\hline \multirow{2}{*}{$\begin{array}{c}\text { Brasil } \\
\text { Profissionalizado }\end{array}$} & Previsto & 33.295 & 90.563 & 172.321 & 233.781 & 529.960 \\
\hline & Realizado & 82.823 & 79.770 & 70.355 & & 232.948 \\
\hline \multirow{2}{*}{ e-Tec } & Previsto & 74.000 & 150.000 & 200.000 & 250.000 & 674.000 \\
\hline & Realizado & 75.364 & 134.341 & 137.012 & & 346.717 \\
\hline \multirow{2}{*}{ Acordo Sistema S } & Previsto & 56.416 & 76.119 & 110.545 & 161.389 & 404.469 \\
\hline & Realizado & 85.357 & 102.807 & 132.289 & & 320.453 \\
\hline \multirow{2}{*}{$\begin{array}{l}\text { Rede Federal de } \\
\text { EPCT }\end{array}$} & Previsto & 72.000 & 79.560 & 90.360 & 101.160 & 343.080 \\
\hline & Realizado & 117.621 & 119.274 & 121.958 & & 358.853 \\
\hline \multicolumn{2}{|c|}{ CURSOS FIC } & 2011 & 2012 & 2013 & 2014 & Total \\
\hline \multirow{2}{*}{ Bolsa-Formação } & Previsto & 226.421 & 590.937 & 743.717 & 1.013 .027 & 2.574 .102 \\
\hline & Realizado & 22.876 & 531.101 & 1.243 .047 & & 1.797 .024 \\
\hline \multirow{2}{*}{ Acordo Sistema S } & Previsto & 421.723 & 570.020 & 821.965 & 1.194 .266 & 3.007 .974 \\
\hline & Realizado & 582.931 & 733.223 & 844.581 & & 2.160 .735 \\
\hline \multicolumn{2}{|c|}{$\begin{array}{l}\text { Total de vagas ofertadas técnico } \\
+\mathrm{FIC}\end{array}$} & 966.972 & 1.802 .057 & 2.854 .208 & 3.104 .936 & 5.922 .869 \\
\hline
\end{tabular}

Acordo Sistema $\mathrm{S}^{6}$

CURSOS FIC

Fonte: MEC (2014, p. 21).

Antes do Plano Nacional de Qualificação do Trabalhador (Planfor), os cursos típicos de educação profissional e tecnológica (EPT) no Brasil eram muito mais longos, durando de dois anos (curso de aprendizagem industrial do Senai) a quatro anos ( $2^{\circ}$ grau técnico profissionalizante). Com o advento do Planfor, quebrou-se o paradigma escolar-temporal da EPT na vertente taylorista-fordista e, hoje, as cargas horárias são cada vez menores. No governo Lula, o Planfor limitou a carga horária dos cursos FIC ao mínimo de 200 horas, mas, no governo Dilma, com o Pronatec, assistimos ao esvaziamento do tempo de formação, com os dados demonstrando a predominância da oferta de cursos de curta duração. Observando o perfil dos cursos predominantes no Pronatec, percebemos como o tipo de oferta do programa assemelha-se ao que é ofertado regularmente pelo Sistema S.

\footnotetext{
6 Refere-se ao Sistema Nacional de Aprendizagem (SNA).

7 FIC, refere-se a cursos de qualificação e ou de formação inicial e continuada, em geral não ultrapassam 450 horas (ver guia FIC pronatec).
} 
Tomando como base os dados de oferta da Bolsa-Formação em 2013, podemos observar, na Figura 1, que o peso relativo do Senai e do Serviço Nacional de Aprendizagem Comercial (Senac) na oferta é muito superior ao das demais instituições; ambos totalizam, juntos, cerca de 63\% do total da oferta desse segmento do Pronatec. Por outro lado, a oferta pelas redes públicas não ultrapassa 20\%, um quinto do total, sendo que a cada dez matrículas no BolsaFormação em 2013, menos de duas ocorreram em espaços públicos.

\section{Figura 1: Participação relativa a cada rede ofertante no Bolsa-Formação} (2013)

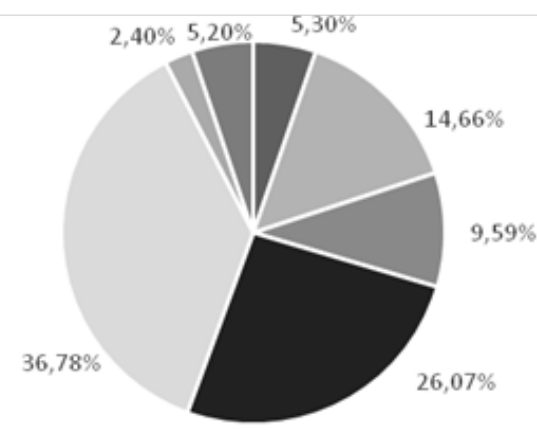

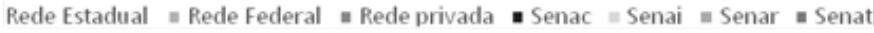

Fonte: MEC (2014, p. 23).

O anuário da qualificação do Dieese (2007) revela que, com o advento dos planos nacionais de qualificação, houve um processo de heterogeneização das instituições ofertantes de qualificação profissional paga com o fundo público. No entanto, sabe-se que nem todas as instituições que vendem esse serviço para o Estado têm ou tinham vocação e capacidade técnica para ofertar educação profissional de qualidade que justifiqasse o repasse do fundo. Lima e Lopes (2005) enumeram várias precariedades nos cursos ofertados pelo Planfor e propõem uma nova metodologia, baseada na ideia tão interessante quanto pouco estudada dos "arcos ocupacionais". A proposta desses autores se materializou por meio dos Planos Nacionais de Qualificação (PNQ) do Ministério do Trabalho e Emprego. O Pronatec, na esteira dos PNQs, reduziu a diversificação dos ofertantes, dando peso majoritário ao Senai, no setor privado, e à Rede Federal, no setor público. 
Essa lógica evidencia-se nos dados mostrados na Tabela 2, que permite uma comparação do número de beneficiários atendidos pelo Bolsa-Formação, tendo em vista a evolução anual de matrículas registradas de 2011 a 2013.

Tabela 2: Evolução do número de matrículas do Pronatec Bolsa-formação na Rede Federal e Senai (2011-2013)

\begin{tabular}{|c|c|c|c|}
\hline Instituição & $\mathbf{2 0 1 1}$ & $\mathbf{2 0 1 2}$ & $\mathbf{2 0 1 3}$ \\
\hline Rede Federal & 117.621 & 119.274 & 121.958 \\
\hline Senai/DN & 25.085 & 514.176 & 876.127 \\
\hline
\end{tabular}

Fonte: Elaboração do autor, a partir de MEC (2014) e MEC (2015).

Ainda em nível nacional, em 2013, a maior incidência de matrículas foi no Senai (876.127). Em contrapartida, a Rede Federal, que tem infraestrutura semelhante em muitos aspectos e superior em outros, tanto em quantidade, qualidade e capilaridade, executou 121.958 matrículas.

Em termos locais, a execução do Pronatec, no acumulado de 2011 a 2014, repete a maior incidência de matrículas no Senai-ES, com 51.856 em cursos FIC e 7.644 em cursos técnicos, totalizando 59.500 matrículas. Em contrapartida, evidencia-se uma participação menor do Ifes, com 9.351 matrículas em cursos FIC e número de matrículas insignificante, em relação ao Senai-ES, em cursos técnicos (SILVA, 2015). Esse fato chama a atenção por dois aspectos: a) os dados verificados reiteram, no nível local, a proeminência das matrículas no Senai-ES, mesmo em um contexto em que a Rede Federal possui uma estrutura física bem maior (21 campi do Ifes x 10 unidades do Senai-ES); b) evidencia-se a oferta irrisória de cursos técnicos pelo Ifes, o que contradita com a vocação formativa mais evidente da instituição. Ao que parece, essa instituição não competiu ou se omitiu na oferta de cursos técnicos, que constituem seu maior knowhow.

Tabela 3: Evolução do número de matrículas do Pronatec Bolsa-formação no Ifes e no Senai-ES (2011-2014)

\begin{tabular}{|c|c|c|c|c|}
\hline \multirow{2}{*}{} & \multicolumn{2}{|c|}{ Ifes } & \multicolumn{2}{c|}{ Senai-ES } \\
\cline { 2 - 5 } & FIC & Técnicos & FIC & Técnicos \\
\hline $\mathbf{2 0 1 1}$ & 1.579 & 0 & 1.364 & 0 \\
\hline $\mathbf{2 0 1 2}$ & 1.087 & 0 & 9.730 & 1.160 \\
\hline $\mathbf{2 0 1 3}$ & 2.929 & 0 & 25.513 & 5.857 \\
\hline $\mathbf{2 0 1 4}$ & 3.756 & 0 & 15.249 & 627 \\
\hline TOTAL & 9.351 & 0 & 51.856 & 7.644 \\
\hline
\end{tabular}

Fonte: Elaboração do autor a partir de MEC (2014) e MEC (2015) 
Nacionalmente, em relação aos recursos repassados a cada rede para execução do Bolsa-Formação, de 2011 a maio de 2014, foi transferido um volume acumulado de cerca de $\mathrm{R} \$$ 6,45 bilhões, assim distribuídos: para o Senai, foram destinados cerca de R \$ 4,52 bilhões; para a Rede Federal, cerca de 1,31 bilhão; para a rede privada (excluindo-se o Sistema S), aproximadamente R\$190 milhões; redes públicas estaduais receberam em torno de $\mathrm{R} \$ 400$ milhões e redes públicas municipais, cerca de R\$18 milhões (BRASIL, 2014).

Nos anos 1990, a crise estrutural do capital colocou em xeque o crescimento industrial, que indicava demanda crescente de mão de obra. Além disso, houve um processo que estancou o movimento de expansão do próprio Estado brasileiro, cujas consequências atingiram a educação escolar do País como um todo, mas também comprometeram o financiamento do Sistema S e da Rede Federal, questionando a validade dos modelos pedagógicos por eles praticados. Nos anos 1990, em pleno governo de Fernando Henrique Cardoso (FHC), a LDB no 9.394/1996, o Decreto n ${ }^{\circ}$ 2.208/1997, a “cefetização” e o Planfor reposicionaram a rede paralela de formação profissional. A crise do compulsório, pago pelas empresas para financiamento do Sistema S, assim como o processo de sucateamento privatizante das escolas públicas, deram as bases neoliberais para a política educacional voltada para essa rede.

Para enfrentar esse processo, desde a ditadura civil-militar, mas, sobretudo a partir de FHC, o governo federal encontrou nos planos nacionais de qualificação (Programa Intensivo de Preparação de Mão-de-obra Industrial, Programa Intensivo de Preparação de Mão-de-obra, Planfor e Pronatec) a alternativa para financiar e manipular o Sistema S e a Rede Federal. Sob o pretexto da necessidade de renovar as metodologias de educação profissional (superar o modelo tayloristafordista e impor a pedagogia das competências), por meio dos planos nacionais de qualificação (Planfor e Pronatec), a política de educação neoliberal (posta em prática nos governos FHC, Lula e Dilma) implantou a solução para o dilema "como formar mais gente com menos recursos dentro do interesse do mercado?". A fórmula empreendida consistiu e consiste em promover uma formação para o mercado por meio do mercado da formação, conforme conceituação dada por Lima (2011). 


\section{CONSIDERAÇÕES FINAIS}

Como podemos perceber, os dados recentes do Pronatec disponibilizados em documentos oficiais da Setec/MEC confirmam que a maior parte dos recursos envolvidos na execução de tal programa tem sido destinada ao Sistema $\mathrm{S}$ e à rede privada, entre cujas instituições se destaca o Senai, que recebeu mais de um terço dos recursos e das matrículas.

A predominância de oferta de cursos FIC, em detrimento da oferta de cursos de maior duração, situa o programa no rol de uma política de educação profissional imediatista e alienante e se configura um tipo de oferta que está longe de dar conta da problemática central que afeta a maior parte da população brasileira, a saber, a elevação da escolaridade integrada à educação profissional e tecnológica, pública e de qualidade.

O Pronatec, como política consistentemente neoliberal, retroage em relação ao movimento de reestruturação do Estado, iniciado de maneira pouco sustentável no governo Lula, representando uma retração do movimento de ampliação do Estado que se verificava, no campo da educação profissional, com a expansão da Rede Federal. Além do mais, tal movimento se adequa perfeitamente ao que Saviani (2010) denomina promiscuidade histórica entre as esferas pública e privada, que vem se perpetuando na educação brasileira.

Para enfrentar o processo de crise do capital e o esvaziamento do Estado num contexto efêmero de crescimento econômico, o governo federal atual, a exemplo de FHC quando da criação Planfor, encontrou no Pronatec a alternativa para solucionar a problemática da formação para o mercado, criando um mercado da formação. Embora o Pronatec tenha entre seus objetivos expandir a rede pública de educação profissional, na disputa pelo fundo público (BRASIL, 2011), a Rede Federal, mesmo estando em condições técnicas e físicas de implementar o Pronatec, participou bem menos que o Senai, tanto em termos nacionais quanto locais, dando à execução do programa abrangência bem mais privada do que pública.

A prioridade na execução de programas em detrimento das políticas de Estado, como a expansão da Rede Federal, atesta uma prática que mobiliza vultosos recursos por meio de políticas que não cumprem objetivos efetivos para a população. Esses programas servem, literalmente, de moeda de troca política e financeira, em que o Estado paga caro por uma educação profissional fragmentada e alienante, incapaz de fazer uma formação integral e emancipadora.

Por fim, o Pronatec se estabelece como mais uma das políticas indutoras de educação profissional que trazem consigo as marcas de ações descoordenadas e pulverizadas em diversos ministérios e que contam com pouca perenidade e 
efetividade social. Nessa direção, reafirmamos a crítica de Lima (2011, p. 496) ao programa, que, no contexto da crise global, insere-se na lógica de solucionar a "problemática da formação para o mercado por meio da criação do mercado da formação".

\section{REFERÊNCIAS}

BOLOGNA, Ítalo. Roberto Mange e sua obra. Goiânia: Unigraf, 1980.

BRASIL, CGU. Relatório de auditoria anual de contas da Secretaria de Educação Profissional e Tecnológica: exercício 2013. Brasília, ago., 2014. Disponível em:<http://sistemas.cgu.gov.br/relats/uploads/RA201406282.pdf>. Acesso em: 20 fev. 2015.

BRASIL, LEI 12.513, de 26 de outubro de 2011. Institui o Pronatec, o Programa Nacional de Inclusão de Jovens (ProJovem); e dá outras providências. Disponível em: <http://www.planalto.gov.br/ccivil_03/_ato2011-2014/2011/lei/112513. htm>. Acesso em: 16 jun. de 2014.

Lei $\mathbf{n}^{\circ}$ 5.154, de 23 de julho de 2004. Regulamenta o $\int 2^{\circ}$ do art. 36 e os arts. 39 a 41 da Lei no 9.394, de 20 de dezembro de 1996, que estabelece as diretrizes e bases da educação nacional, e dá outras providências. Disponível em: <http://www.planalto.gov.br/ccivil_03/_ato2004-2006/2004/decreto/d5154. htm>. Acesso em: 22 jul. 2015.

Lei $\mathbf{n}^{\circ} \mathbf{5 . 6 9 2}$, de 11 de agosto de 1971. Fixa diretrizes e bases para o ensino de $1^{\circ}$ e $2^{\circ}$ graus, e dá outras providências. Disponível em: <http:/ /www. planalto.gov.br/CCIVIL_03/leis/L5692.htm>. Acesso em: 22 jul. 2015.

Lei $\mathbf{n}^{\circ}$ 5.154, de 23 de julho de 2004. Regulamenta o $\ 2^{\circ}$ do art. 36 e os arts. 39 a 41 da Lei no 9.394, de 20 de dezembro de 1996, que estabelece as diretrizes e bases da educação nacional, e dá outras providências. Disponível em: <http://www.planalto.gov.br/ccivil_03/_ato2004-2006/2004/decreto/d5154. htm>. Acesso em: 22 jul. 2015.

Lei $\mathbf{n}^{\circ} \mathbf{5 . 6 9 2}$, de 11 de agosto de 1971. Fixa diretrizes e bases para o ensino de $1^{\circ}$ e $2^{\circ}$ graus, e dá outras providências. Disponível em: <http:/ /www. planalto.gov.br/CCIVIL_03/leis/L5692.htm>. Acesso em: 22 jul. 2015. 
Decreto $\mathbf{n}^{\mathbf{0}} \mathbf{7 . 5 6 6}$, de 23 de setembro de 1909. Cria nas capitais dos Estados as Escolas de Aprendizes Artífices, para o ensino profissional primário e gratuito. Disponível em: <http://portal.mec.gov.br/setec/arquivos/pdf3/ decreto_7566_1909.pdf>. Acesso em: 22 jul. 2015.

Decreto $\mathbf{n}^{\mathbf{0}} \mathbf{2 2 0 8}$, de 17 de abril de 1997. Regulamenta o $\int 2^{\circ}$ do art. 36 e os arts. 39 a 42 da Lei no 9.394, de 20 de dezembro de 1996, que estabelece as diretrizes e bases da educação nacional. Disponível em: $<<$ http:/ /www.planalto. gov.br/ccivil_03/decreto/D2208.htm>> Acesso em 22 jul 2015.

BRYAN, N A P Educação, Trabalho e Tecnologia São Paulo / SP, 1992, 524p. Tese (Doutorado em Educação). Campinas: Faculdade de Educação, UNICAMP.

CUNHA, L. A. O ensino industrial-manufatureiro no Brasil. Revista Brasileira de Educação, n. 14, p. 89-107, 2000.

DIEESE. Anuário da qualificação social e profissional: 2006. São Paulo, 2007.

INSTITUTO FEDERAL DE EDUCAÇÃO, CIÊNCIA E TECNOLOGIA DO ESPÍRITO SANTO. Pró-reitoria de Desenvolvimento Institucional. Relatório de gestão: exercício 2013. Vitória, mar. 2014. Disponível em: < http:/ / prodi.ifes. edu.br/prodi/relatorio_gestao/Relatorio_de_Gestao_2013.pdf>. Acesso em: 14 abr. 2015.

FONSECA, C S A História do ensino industrial Rio de janeiro: Senai, V01-05, 1986.

KUENZER, A reforma do ensino técnico no Brasil e suas consequências. In: FERRETI, C. J.; SILVA JUNIOR, J. dos R.; OLIVEIRA, M. R. N. (Org.). Trabalho, formação e currículo: para onde vai a escola? São Paulo: Xamã, 1999. p. $127-140$.

LIMA, A. A. B.; LOPES, F. Diálogos sociais: experiências e propostas.Brasília: Ministério do Trabalho e Emprego/SPPE/DEQ, 2005.

LIMA, M A. História da formação profissional: os passos e descompassos históricos do Senai-ES com os paradigmas da produção no Espírito Santo. Vitória: Autor, 2007. 
Desenvolvimento histórico do tempo socialmente necessário da educação profissional Vitória: autor , 2010.

Perspectivas e riscos da educação profissional do governo Dilma: educação profissional local e antecipação ao Programa Nacional de Acesso à Escola Técnica (Pronatec), Associação Nacional de Pós-graduação e Pesquisa em Educação. 34. Anais ... Natal:, 2011.

MANGE, R. Diretrizes traçadas para o ano de 1953. Informativo Senai, São Paulo, 1953.

MEC. Secretaria de Educação Profissional e Tecnológica. Relatório de gestão do exercício de 2013. Brasília, 2014. Disponível em: <http://portal.mec. gov.br $/$ index.php?option $=$ com_docman $\&$ view $=$ download $\&$ alias $=15996-$ relatorio-gestao-exercicio-2013-setec-pdf\&category_slug=julho-2014pdf\&Itemid=30192> . Acesso em: 16 abr. 2015.

Sistema Nacional de Informações da Educação Profissional e Tecnológica. Disponível em: <http://sitesistec.mec.gov.br/resultados/255resultado>. Acesso em: 10 jul. 2015.

Expansão da Rede Federal. Disponível em: $<$ http://redefederal.mec. gov.br/expansao-da-rede-federal>. Acesso em: 5 out. 2015.

PRONATEC. Disponível em: < http://www.sistemafindes.org.br/senai/portal/ index.php?option $=$ com_content\&view $=$ article $\&$ id $=287 \&$ Itemid $=203>$. Acesso em: 20 set. 2015.

Guia pronatec de cursos FIC Brasília: 2013 Disponível em $<<$ http://pronatec.mec.gov.br/fic/pdf/2013_guia_cursosfic_port_899.pdf $>>$ Acesso em: 20 set. 2015.

MEDEIROS, M M de Expansão capitalista e ensino industrial Rio de Janeiro: SENAI/DN/DPEA, 1987.

SAVIANI, D. O Estado e a promiscuidade entre o público e o privado na história da educação brasileira. In: SAVIANI, Dermeval. (Org.). Estado e políticas educacionais na história da educação brasileira. Vitória: Edufes, 2010. p. 1544. 
SENAI e Pronatec. Disponível em: <http://www.portaldaindustria.com.br/ senai/canal/voce-na-industria-home/>. Acesso em: 20 set. 2015.

SENAI. O que é o SENAI. Disponível em: < http://www.portaldaindustria. com.br/senai/institucional/2015/05/1,1773/o-que-e-o-senai.html>. Acesso em: 10 jul. 2015.

SILVA, M. I. C. da. Pronatec e as artes de governar: capturas e apropriações em uma escola federal do Espírito Santo. 2015. 234 f. Dissertação (Mestrado em Educação) - Universidade Federal do Espírito Santo, Vitória, 2015. <http:// portais4.ufes.br/posgrad/teses/tese_8955_MARIA\%20IZABEL.pdf>. Acesso em: 21 jul. 2015.

MARCELO LIMA possui graduação em Pedagogia pela Universidade Federal do Espírito Santo (1994), mestrado em Educação pela Universidade Federal do Espírito Santo (1999 - pesquisa sobre o SENAI) e doutorado em Educação pela Universidade Federal Fluminense (2004 - pesquisa sobre o IFES) e especialização em Gestão do Conhecimento pela Universidade Federal do Espírito Santo (2007 - catálogo de mestres e doutores do ES). É professor adjunto do Centro Pedagógico da UFES na cadeira de Política e Fudamentos da Educação. Tem experiência na área de Educação Profissional, com ênfase em Economia da Educação, atuando principalmente nos temas da educação, recursos humanos, criminalidade, trabalho, ensino médio, educação profissional e tecnológica. E-mail: marcelo.lima@ufes.br

ZILKA SULAMITA TEIXEIRA DE AGUILAR PACHECO é pedagoga pela UFES e mestranda em Educação no PPGE-UFES.E-mail: zilkasteixeira@gmail.com

ANA PAULA RIBEIRO FERREIRA é assistente social da UFES e mestranda em Educação no PPGE-UFES. E-mail: anaprif26@gmail.com

SAMANTA LOPES MACIEL é pedagoga do IFES e mestranda em Educação do PPGE-UFES. E-mail: samanta.ifes@gmail.com 